\title{
Resensi Buku: Bimbingan Konseling Anak Berkebutuhan Khusus
}

\author{
Mahmudah $^{1}$, Nur Intan Maharani I. ${ }^{2}$, Musmita Ismail ${ }^{2}$, Ildayanty $^{2}$ \\ ${ }^{1}$ Jln. Mallengkeri Raya, Makassar, Universitas Negeri Makassar (Kampus Parangtambung) \\ Mahmudah.mahfud@unm.ac.id \\ ${ }^{2}$ Program Studi Pendidikan Khusus, Fakultas Ilmu Pendidikan, Universitas Negeri Makassar
}

\begin{abstract}
ABSTRAK
Resensi buku merupakan karya ilmiah yang memuat penilaian terhadap buku yang menghasilkan suatu ulasan. Tujuan dari penulisan resensi buku adalah untuk menginformasikan kepada pembaca tentang isi buku serta memberikan masukan kepada penulis. Secara umum isi resensi buku meliputi identitas buku, sinopsis atau intisari buku, biografi penulis, kelebihan dan kekurangan buku, serta kesimpulan. Kesimpulan isi resensi memuat pandangan penulis apakah buku yang diresensi layak dibaca khalayak umum atau menginformasikan target pembaca yang sesuai dengan isi buku.
\end{abstract}

Kata kunci: Resensi Buku, Artikel Semi Ilmiah, Bimbingan Konseling, Anak Berkebutuhan Khusus.

\section{PENDAHULUAN}

Resensi buku ini ditulis untuk memenuhi tugas UTS Mata Kuliah Bahasa Indonesia, Program Studi Pedidikan Khusus, Fakultas Ilmu Pendidikan, Universitas Negeri Makassar. Semoga pembaca dapat memetik manfaat dari penulisan resensi buku dari kami meskipun penulisan resensi buku ini masih jauh dari sempurna, untuk itu kami harap adanya kritik dan saran dari pembaca agar dapat mengembangkan keterampilan menulis dan analisa kami pada kesempatan yang akan datang.

Adapun buku yang akan diresensi adalah buku yang ditulis dan diterbitkan secara luas pada tahun 2020 sebagai salah satu referensi dan literatur disiplin ilmu terkait pelaksanaan Program Studi Pendidikan Khusus/Pendidikan Luar Biasa yakni Bimbingan Konseling. 


\section{PEMBAHASAN}

\section{Identitas Buku}

Judul

: PEMBINAAN ANAK

BERKEBUTUHAN KHUSUS (Sebuah

Perspektif Bimbingan dan Konseling)

Penerbit : Yayasan Kita Menulis

Tebal Buku : 296 halaman

Ukuran Buku : $16 \times 23 \mathrm{~cm}$

Bahasa : Bahasa Indonesia

Cetakan : Januari 2020

ISBN $\quad$ : 978-623-7645-24-5
SEBUAH PERSPEKTIF BIMBINGAN DAN KONSELING PEMBINAAN ANAK BERKEBUTUHAN KHUSUS

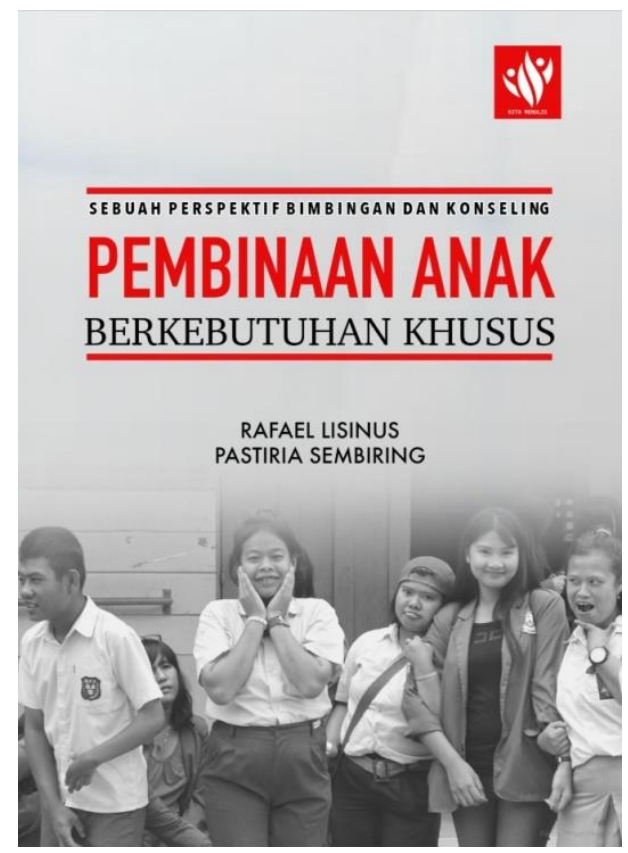

\section{Intisari Buku}

Buku yang berjudul "PEMBINAAN ANAK BERKEBUTUHAN KHUSUS (Sebuah Perspektif Bimbingan dan Konseling)" ini membahas tentang berbagai komponen tentang bimbingan konseling Anak Berkebutuhan Khusus dan memberikan wawasan tentang masingmasing jenis ABK yang ditulis dan diuraikan secara terpisah setiap bab dengan total 20 bab. Contoh isi bab yang tertulis dalam buku ini yaitu:

- BAB 1 Bimbingan Dan Konseling Anak Berkebutuhan Khusus

Pada bab ini menjelaskan pengertian dan jenis-jenis dari anak berkebutuhan khusus, tujuan bimbingan, dan konseling Anak Bekebutuhan Khusus.

- $\quad$ BAB 2 Model Pendidikan Anak Berkebutuhan Khusus

Menjelaskan tentang konsep, implementasi, sekolah penyelenggara, kurikulum pendidikan inklusif, dan ragam model pendidikan anak berkebutuhan khusus.

- BAB 3 Identifikasi Anak Berkebutuhan Khusus

Pada bab ini dijelaskan tujuan identifikasi Anak Berkebutuhan Khusus, prinsip-prinsip identifikasi Anak Berkebutuhan Khusus serta sasaran identifikasi Anak Berkebutuhan Khusus. 
- BAB 4 Asesmen Anak Berkebutuhan Khusus

Menjelaskan tentang konsep dasar asesmen, tujuan asesmen secara umum, prosedur asesmen, bentuk instrumen asesmen, dan prosedur pengembangan instrumen asesmen dalam berkebutuhan khusus.

- BAB 5 Tunanertra

Pada bab ini dijelaskan tentang pengertian tunanetra, klasifikasi anak tunanetra, keterbatasan tunanetra, penyebab tunanetra, dan penanganan anak tunanetra.

- BAB 6 Tunarungu

Pada bab ini dijelaskan apa itu tunarungu, apa yang menyebabkan seseorang bisa menjadi tunarungu, dan penangan yang bisa kita lakukan terkait penyandang tunarungu.

Diatas merupakan beberapa contoh dari isi beberapa bab dalam buku tersebut. Buku ini mengupas tuntas mulai dari pengertian, penyebab, klasifikasi, implikasi, serta penanganan yang tepat bagi Anak Berkebutuhan Khusus. Selain ABK yang diuraikan diatas, buku ini juga menguraikan jenis ABK lainnya yaitu tunawicara, tunagrahita, tunadaksa, tunalaras, diskalkulia, disgrafia, disleksia, Asperger disorder, autisme, cerebral palsy, hiperaktif, slow learner, dan anak berbakat (genius, anak keatif, dan anak indigo). Buku ini juga menguraikan tentang program Bimbingan Konseling bagi Anak Berkebutuhan Khusus di sekolah yang meliputi visi misi, dasar hukum, rumusan kebutuhan, komponen program BK, evaluasi, anggaran dan lain-lain.

\section{Biografi Penulis}

Dra. Pastiria Sembiring B.A, M.Pd lahir pada tanggal 8 Agustus 1955. Ia memperoleh gelar S1 dan Gelar Magister Pendidikan (S2) di IKIP Medan. Sekarang beliau menjabat sebagai Lektor Kepala dan menjadi salah satu dosen tetap di Fakultas Ilmu Pendidikan Universitas Negeri Medan dengan prodi Bimbingan Konseling.

Rafael Lisinus Ginting S.Pd, M.Pd. Lahir pada tanggal 26 Juni 1985. Pada tahun 2010 memperoleh gelar Sarjana Pendidikan (S.Pd) Fakultas Ilmu Pendidikan jurusan Psikologi Pendidikan dan Bimbingan Universitas Negeri Medan (UNIMED), gelar Magister Pendidikan (S2) 2013 dari Universitas Pendidikan Indonesia. Beliau sekarang menjadi dosen 
tetap Fakultas Ilmu Pendidikan Universitas Negeri Medan dengan prodi Bimbingan Konseling.

\section{Kelebihan dan Kekurangan Buku}

Kelebihan buku ini yaitu materi yang disajikan sangat lengkap dengan bahasa Indonesia yang baku dan lugas. Buku ini mengupas tuntas tentang Bimbingan Konseling serta jenis-jenis Anak Berkebutuhan Khusus yang terurai lengkap dan sistematis. Selain itu, desain sampulnya menarik meskipun dengan warna dasar monokrom namun dipadukan dengan warna merah cerah yang mencolok sehingga meninggalkan kesan yang kuat pada judul yang tertera pada buku.

Sedangkan kekurangan buku ini yaitu kurangnya gambar-gambar yang mengvisualisasikan materi-materi yang tertulis, setiap pergantian bab tidak disajikan gambar ilustrasi sehingga ketika membaca buku akan menjadi mudah bosan atau mengantuk. Selain itu, spasi antara paragraf sebelumnya dengan judul sub-bab semua berjarak sama, meskipun terlihat rapi namun terkesan monoton apalagi jika tidak didukung dengan gambar ilustrasi.

\section{Kesimpulan}

Buku ini sangat direkomendasikan bagi calon guru Pendidikan Khusus karena materi yang disajikan sangat komplit. Tak menutup kemungkinan bagi masyarakat awam dari semua kalangan dan umur untuk membacanya karena buku ini juga menyajikan tentang Anak Berkebutuhan Khusus secara keseluruhan mulai dari pengertian hingga penanganannya sehingga dapat menambah wawasan jika sewaktu-waktu berkesempatan untuk bertemu dan berinteraksi langsung dengan Anak Berkebutuhan Khusus. 